\title{
Endoscopic closure using over-the-scope clip for delayed colonic perforation after hybrid endoscopic submucosal dissection
}

A 68-year-old woman was found to have a flat elevated lesion, which was approximately $20 \mathrm{~mm}$ in size and located in the hepatic flexure. The patient underwent endoscopic submucosal dissection (ESD) for the lesion, and en bloc resection was achieved without intraoperative perforation ( $\triangleright$ Fig.1a). A few endoclips were applied prophylactically to close tiny injuries to the muscularis propria ( $\bullet$ Fig. 1 b). Two days after the endoscopic treatment, the patient started to experience severe lower abdominal pain and nausea, and computed tomography (CT) revealed free air (\$Fig.2). After discussion with surgeons, it was decided to close the perforation endoscopically because there was no ascites or abscess.

During colonoscopy, brown intestinal juice was observed. The ulceration from the endoscopic treatment was red and edematous, and a perforation was confirmed ( Fig.3a). As the perforation was relatively large and thick, we decided to use an over-the-scope clip (OTSC, $12 / 6 \mathrm{t}$; Ovesco, Tübingen, Germany) in order to firmly close the whole wall defect. After suctioning the perforated part into the cap, the OTSC device was released, and the wound was closed successfully ( $>$ Fig.3b, $\mathbf{3}$ Video $\mathbf{1}$ ). The patient was discharged home 12 days after ESD.

Several reports have described the feasibility of using OTSCs for delayed perforation in the upper gastrointestinal tract [1, 2]. However, delayed perforation after colonic ESD usually requires emergency surgery. In the current case, the delayed perforation was diagnosed early by CT scan, allowing the wound to be treated endoscopically and without drainage. Recent reports have described how the use of polyglycolic acid sheets and fibrin glue or endoclips has avoided emergency surgery $[3,4]$. However, the opposition forces of OTSCs are much stronger and may result in a more secure closure, thus avoiding emergency surgery.
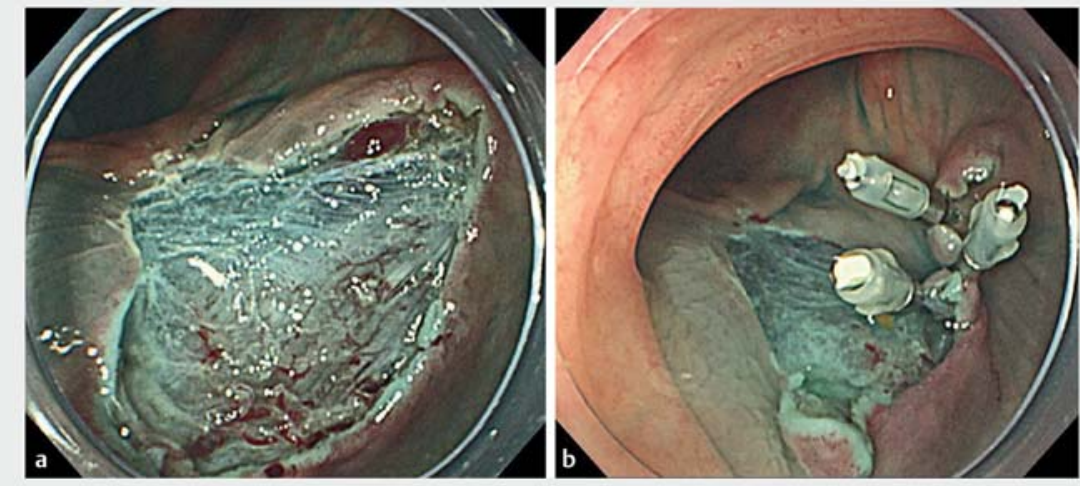

- Fig. 1 Endoscopic view. a No perforation was apparent after colorectal endoscopic submucosal dissection. $\mathbf{b}$ Endoclips were applied prophylactically to close tiny injuries to the muscularis propria.

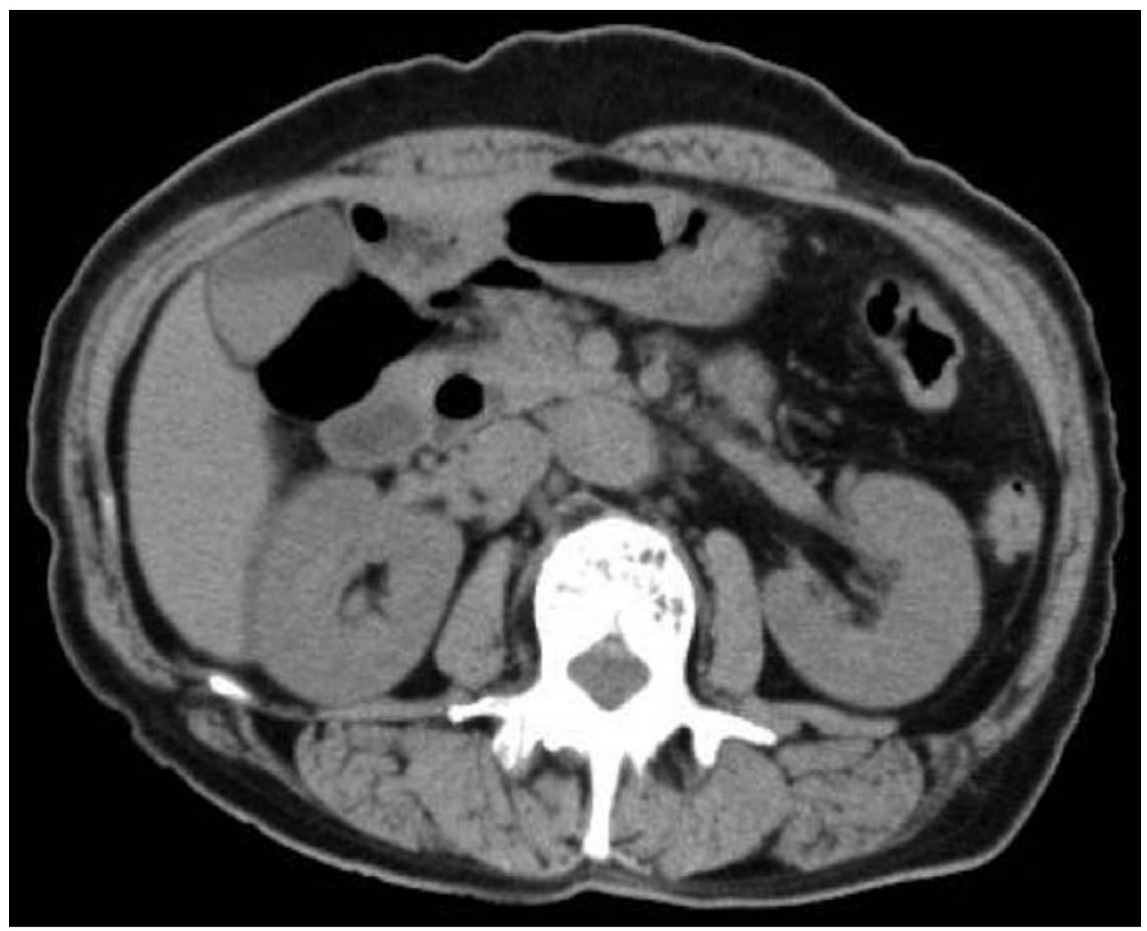

- Fig. 2 Free air was recognized around the gallbladder bed.

Endoscopy_UCTN_Code_CPL_1AJ_2AG

Competing interests

The authors declare that they have no conflict of interest. 

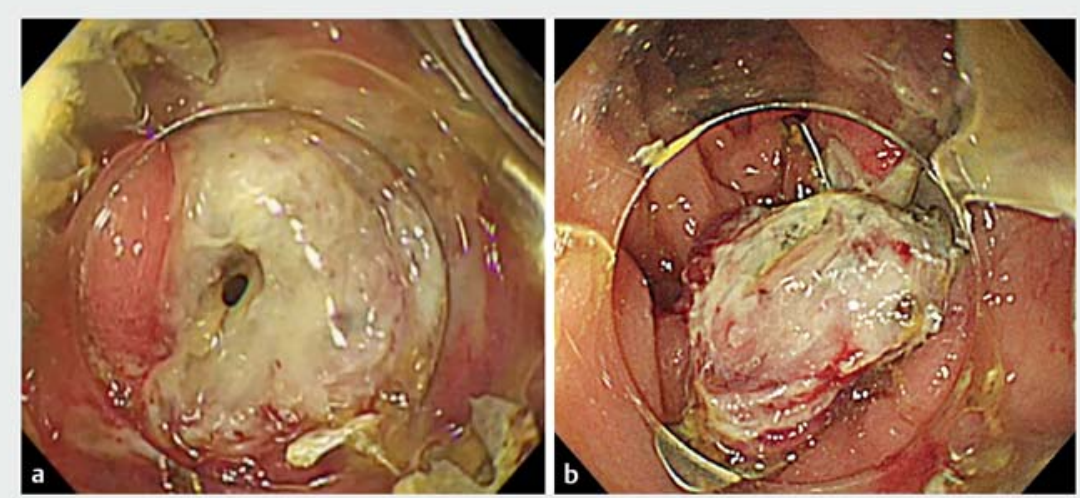

- Fig. 3 Closure of the perforation using an over-the-scope clip (OTSC). a Full suction around the delayed perforated part. $\mathbf{b}$ The OTSC device was directed toward the perforation, the clip was released, and the wound was closed successfully.

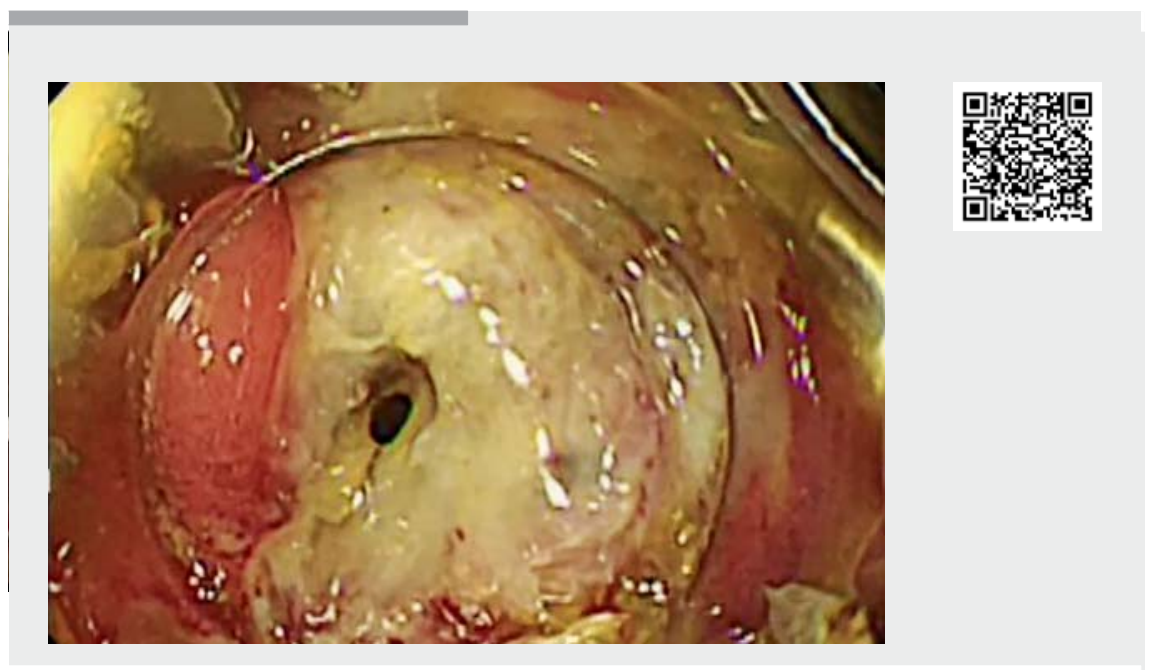

$\checkmark$ Video 1 Endoscopic closure using an over-the-scope clip for delayed colonic perforation after hybrid endoscopic submucosal dissection of a lesion in the transverse colon.

The authors

\section{Hiroki Kuwabara, Hideyuki Chiba, Jun Tachikawa, Naoya Okada, Jun Arimoto, Michiko Nakaoka}

Department of Gastroenterology, Omori Red Cross Hospital, Tokyo, Japan

\section{Corresponding author}

\section{Hideyuki Chiba, MD, PhD}

Department of Gastroenterology, Omori Red Cross Hospital, 4-30-1 Chuo, Ota-ku, Tokyo, 143-0024, Japan Fax: +81-3-37760004 h.chiba04@gmail.com

\section{References}

[1] Abe S, Minagawa T, Tanaka $\mathrm{H}$ et al. Successful endoscopic closure using over-the-scope clip for delayed stomach perforation caused by nasogastric tube after endoscopic submucosal dissection. Endoscopy 2017; 49: E56-57

[2] Ngo E, Born P, Strebel H. Endoscopic treatment of an oesophageal rupture using an over-the-scope clip (OTSC): a case report. Arab J Gastroenterol 2015; 16: 139-141

[3] Nagami Y, Fukunaga S, Kanamori A et al. Endoscopic closure using polyglycolic acid sheets for delayed perforation after colonic endoscopic submucosal dissection. Endoscopy 2020; 52: E11-E12

[4] Inoki K, Sakamoto T, Sekiguchi M et al. Successful endoscopic closure of a colonic perforation one day after endoscopic mucosal resection of a lesion in the transverse colon. World J Clin Cases 2016; 4: 238-242

\section{Bibliography}

DOI https://doi.org/10.1055/a-1134-4508

Published online: 27.3.2020

Endoscopy 2020; 52: E368-E369

(c) Georg Thieme Verlag KG

Stuttgart · New York

ISSN 0013-726X

\section{ENDOSCOPY E-VIDEOS}

https://eref.thieme.de/e-videos

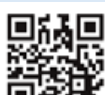

Endoscopy E-Videos is a free access online section, reporting on interesting cases and new techniques in gastroenterological endoscopy. All papers include a high quality video and all contributions are freely accessible online.

This section has its own submission website at

https://mc.manuscriptcentral.com/e-videos 